\title{
Multiple overlapping stent-assisted coiling improves efficacy and safety of treatment for complex intracranial aneurysms: a randomized trial
}

\author{
Lingtong You, Jiaxin Huang, Jinning Zhang and Zhixian Jiang*
}

*Correspondence:
jzx00137@126.com

Inpatient Department District

N13, Quanzhou First Hospital

Affiliated to Fujian Medical

University, Chendong Branch

of Quanzhou 1st Hospital,

Quanzhou 362000, Fujian,

China

\begin{abstract}
Background: Intracranial aneurysm rupture is the main cause of subarachnoid hemorrhage, leading to high disability and mortality. This study aimed to evaluate the clinical treatment effects of multiple overlapping stent-assisted coiling for complex intracranial aneurysms.
\end{abstract}

Methods: We conducted a randomized, controlled, single-blinded clinical trial among 168 patients diagnosed with complex intracranial aneurysms. Treatment allocation to either single stent (SS) group or multiple stent (MS) group was randomized at 1:1 ratio using a Web-based platform. The O'Kelly-Marotta (OKM) grading scale was used to evaluate the degree of aneurysm occlusion after operation and during follow-up. Good aneurysm occlusion was defined as OKM grade C-D. The modified Rankin Scale (mRS) was used to evaluate the neurological status and the clinical outcome of patients.

Results: Efficacy comparative analysis demonstrated that major recurrence of aneurysms was significantly reduced in the MS group $(P=0.012)$. In addition, the MS group displayed significantly reduced number of patients with mRS between 3 and 6 $(P=0.007)$ and increased number of patients with mRS between 0 and $1(P=0.034)$. Furthermore, the MS group showed increased percentage of patients with OKM grade $\mathrm{C}-\mathrm{D}(P=0.041)$. Compared with the SS group, the MS group exhibited decreased mortality $(P=0.037)$ and morbidity $(P=0.035)$.

Conclusions: Multiple overlapping stent-assisted coiling significantly improved the clinical treatment effects and provided a new method for complex intracranial aneurysms.

\section{Highlights}

- Multiple overlapping stent-assisted coiling technique reduced the major recurrence of aneurysms compared with single stent.

- Multiple overlapping stent-assisted coiling improved neurological status of patients with aneurysms compared with single stent.

(c) The Author(s) 2021. Open Access This article is licensed under a Creative Commons Attribution 4.0 International License, which permits use, sharing, adaptation, distribution and reproduction in any medium or format, as long as you give appropriate credit to the original author(s) and the source, provide a link to the Creative Commons licence, and indicate if changes were made. The images or other third party material in this article are included in the article's Creative Commons licence, unless indicated otherwise in a credit line to the material. If material is not included in the article's Creative Commons licence and your intended use is not permitted by statutory regulation or exceeds the permitted use, you will need to obtain permission directly from the copyright holder. To view a copy of this licence, visit http:// creativecommons.org/licenses/by/4.0/. The Creative Commons Public Domain Dedication waiver (http://creativecommons.org/publicdomain/zero/1.0/) applies to the data made available in this article, unless otherwise stated in a credit line to the data. 
- Multiple stent-assisted coiling decreased the aneurysm occlusion after operation compared with single stent.

- Multiple overlapping stent-assisted coiling significantly improved the clinical treatment for complex intracranial aneurysms.

Keywords: Intracranial aneurysms, Multiple overlapping stent-assisted coiling, O'Kelly-Marotta (OKM) grade, modified Rankin Scale (mRS)

\section{Background}

Intracranial complex aneurysms and aneurysm rupture result in subarachnoid hemorrhage and seriously affect the life quality of patients $[1,2]$. Pathological dilations at branching cerebral arteries typically develop in middle-aged patients and affect 3 to $5 \%$ of the adults worldwide [3, 4]. Approximately $20 \%$ of patients with intracranial aneurysm harbor more than one aneurysm at their brain and cranial base [5]. Complex aneurysms, including large and giant aneurysms, fusiform-shaped aneurysms, wide-necked aneurysm, or small aneurysm that are unsuitable for coil embolization, are still challenging to be treated $[6,7]$. Their special aneurysm-neck shapes, multiple perforating vessels and special locations can easily induce high-risk aneurysm rupture, thus leading to progressive neurological deficit, subarachnoid hemorrhage and thrombosis [8].

Endovascular therapy is an emerging discipline that integrates imaging diagnosis and clinical treatment [9]. Puncture needles, catheters and other endovascular devices are used to introduce specific devices into human body lesions through natural orifices or tiny wounds for minimally invasive treatments [9]. Imaging equipments, such as digital subtraction angiography, computer tomography (CT), ultrasound, and magnetic resonance, provide guidance and monitoring for endovascular therapy [10]. The application of endovascular therapy in diagnosis and forestry inspection has made breakthrough progress with the development of artificial intelligence [11]. Endovascular treatment has become an important method for the treatment of complex aneurysms.

Current strategies for treating complex intracranial aneurysms mainly include craniotomy and endovascular coil embolization [12,13]. For instance, endovascular treatment, especially pipeline embolization, has been widely considered to be a more efficient way for the management of intracranial aneurysms due to its minimal invasion and higher safety, despite the advances in craniotomy techniques [14]. It has been reported that the Willis covered stent and the Pipeline flow-diverter stent can be used to embolize the internal carotid aneurysms with coils [15]. These techniques have achieved positive results in clinical practice [16]. However, the shortcomings of the single stent-assisted coiling technique, including the insufficient support or inadequate mesh density in the treatment of complex intracranial aneurysms, can lead to frequent aneurysm recurrence and multiple thromboembolic complications [17]. Studies targeting multiple overlapping stenting technology are still limited.

The practice of the overlapping stent-assisted coiling techniques is still limited in clinic. Multiple stents have been used to successfully reconstruct dissecting or blood blister-like aneurysms with wide-necked and fusiform structures [18]. Moreover, accumulating evidence has demonstrated that multiple overlapping stent-assisted coiling technology helps protect the parent arteries affected by aneurysms and decrease the 
incidence of coil protrusion and branch occlusion [19]. A Korean research has also demonstrated that overlapping stent-assisted coiling technique is feasible and effective for the treatment of recurrent aneurysms after stent-assisted coiling [18].

In this study, we utilized multiple stents and single stent in the endovascular coil embolization of complex intracranial aneurysms. Our study aimed to evaluate the clinical treatment effects of multiple overlapping stent-assisted coiling for complex intracranial aneurysms. We firstly demonstrated that multiple overlapping stent-assisted coiling technology could not only keep the supporting force of stent-assisted coils to the inner wall of blood vessels, but also more densely embolize aneurysms and prevent their recurrence.

\section{Results}

\section{Procedure of the research}

To demonstrate the effect of overlapping stent-assisted coiling on the treatment of complex intracranial aneurysms, a randomized and single-blinded clinical trial was performed. A total of 168 patients meeting criteria were recruited and assessed for our study (Fig. 1). Participants were randomly divided into the single stent (SS) group or the multiple stent (MS) group at a ratio of 1:1 using a Web-based platform. Among all the participants, 9 patients discontinued our intervention, 8 patients moved away and lost contact, 3 participants changed their mind and refused to join this study anymore, and 4 patients withdrew for other personal reasons. Thus, the data were collected from the remaining 144 participants (71 in SS group and 73 in MS group) for follow-up analysis.

\section{Basic clinical characteristics of the participants}

The basic clinical characteristics of all participants were collected and shown in Table 1. The demographic parameters included age, gender, the baseline of modified Rankin Scale (mRS) and National Institute of Health Stroke Scale (NIHSS), the number, morphology, location and size of aneurysms. As shown in Table 1, no significant differences

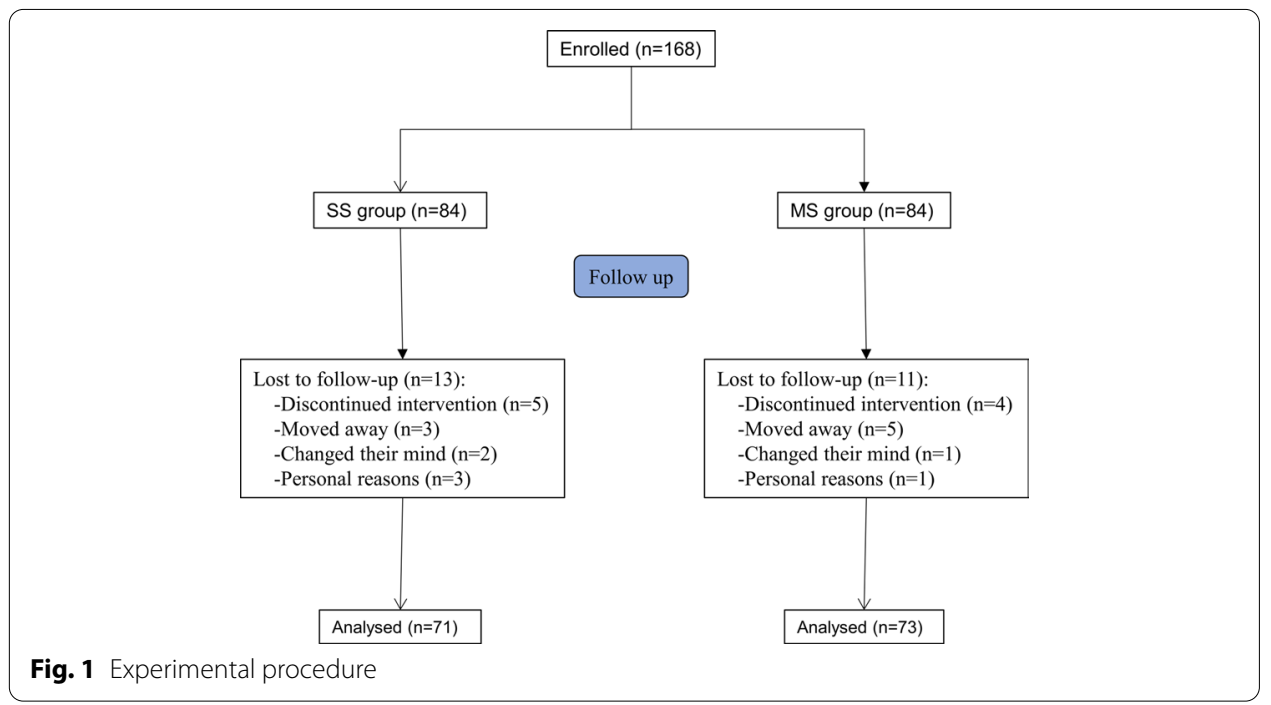


Table1 Characteristics of patients and aneurysms

\begin{tabular}{|c|c|c|c|}
\hline & SS group $(n=71)$ & MS group $(n=73)$ & $P$ value \\
\hline \multicolumn{4}{|l|}{ Sex } \\
\hline Female, $n(\%)$ & $57(80.5)$ & $60(82.7)$ & 0.549 \\
\hline Age (mean) (SD) (year) & $49.5(11.3)$ & $50.6(10.7)$ & 0.286 \\
\hline Baseline mRS, mean (SD) & $0.2(0.4)$ & $0.2(0.3)$ & 0.367 \\
\hline Baseline NIHSS, mean (SD) & $0.1(0.5)$ & $0.1(0.6)$ & 0.781 \\
\hline Multiple aneurysms (no.) (\%) & $19(26.8)$ & $18(24.7)$ & 0.231 \\
\hline \multicolumn{4}{|l|}{ Ruptured aneurysms, n (\%) } \\
\hline Treatment group & $27(38.0)$ & $26(35.6)$ & 0.495 \\
\hline Recurrence & $2(2.8)$ & $1(1.4)$ & 0.201 \\
\hline \multicolumn{4}{|l|}{ Unruptured aneurysms, n (\%) } \\
\hline Treatment group & $44(62.0)$ & $47(64.4)$ & 0.364 \\
\hline Recurrence & $3(4.2)$ & $5(6.8)$ & 0.172 \\
\hline Symptomatic & $4(5.6)$ & $7(9.6)$ & 0.075 \\
\hline \multicolumn{4}{|l|}{ Aneurysm size (maximal diameter) } \\
\hline Mean $(\mathrm{SD})(\mathrm{mm})$ & $7.9(3.7)$ & $7.8(4.1)$ & 0.544 \\
\hline \multicolumn{4}{|l|}{ Aneurysm neck } \\
\hline Mean (SD) (mm) & $3.0(1.0)$ & $2.9(1.2)$ & 0.297 \\
\hline Neck $\geq 4.0(\mathrm{~mm}), n(\%)$ & $23(32.4)$ & $25(35.2)$ & 0.272 \\
\hline Aneurysm location, anterior, $n$ (\%) & $46(64.8)$ & $46(63.0)$ & 0.483 \\
\hline Internal carotid & $20(28.2)$ & $22(30.1)$ & 0.372 \\
\hline Anterior cerebral & $17(23.9)$ & $16(21.9)$ & 0.225 \\
\hline Middle cerebral & $9(12.7)$ & $8(11.0)$ & 0.317 \\
\hline Aneurysm location, posterior, $n(\%)$ & $25(35.2)$ & $27(37.0)$ & 0.349 \\
\hline Basilar & $19(26.8)$ & $20(27.4)$ & 0.545 \\
\hline Other posterior & $6(8.5)$ & $7(9.6)$ & 0.270 \\
\hline
\end{tabular}

mRS modified Rankin Scale, NIHSS National Institute of Health Stroke Scale

were observed of any above characteristics between participants in these two groups at the beginning of our research $(P>0.05)$.

\section{Efficacy comparative analysis between the two groups}

In order to compare the treatment effects of the SS and MS group, we compared the primary outcomes and clinical outcomes of two groups (Table 2). The primary outcomes included major recurrence, retreatment, initial treatment failure, subarachnoid aneurysm hemorrhage $(\mathrm{SAH})$, related mortality, and related morbidity. We found that the percentage of patients with major recurrence and retreatment was significantly reduced in the MS group compared to the SS group ( $P=0.012$ and $P=0.023$, respectively). However, no significant differences were observed in initial treatment failure, $\mathrm{SAH}$, related mortality, and related morbidity between the two groups. The clinical outcomes were evaluated by mRS score and the O'Kelly-Marotta (OKM) grade. Our results showed that the MS group showed significantly reduced number of patients with mRS between 3 and $6(P=0.007)$ and increased number of patients with mRS between 0 and $1(P=0.034)$, indicating that the neurological symptoms caused by surgery in the MS group were decreased. In addition, the MS group exhibited increased percentage of patients with OKM grade $\mathrm{C}-\mathrm{D}(P=0.041)$, suggesting that multiple overlapping stent-assisted coiling 
Table2 Efficacy comparative analysis between the two groups

\begin{tabular}{lccc}
\hline & SS group $(\mathbf{n}=\mathbf{7 1})$ & MS group $(\mathbf{n}=\mathbf{7 3})$ & P value \\
\hline Primary outcome & & & \\
Major recurrence & $37(52.1)$ & $29(39.7)$ & 0.012 \\
Retreatment & $8(11.2)$ & $5(6.8)$ & 0.023 \\
Initial treatment failure & $3(4.2)$ & $4(5.5)$ & 0.067 \\
SAH & $1(1.4)$ & $1(1.4)$ & 0.583 \\
Related mortality & $4(5.6)$ & $1(1.4)$ & 0.457 \\
Related morbidity & $2(2.8)$ & $1(1.4)$ & 0.353 \\
Clinical outcome & & & \\
mRS & & & \\
$3-6$ & $5(7.0)$ & $1(1.4)$ & 0.007 \\
2 & $3(4.2)$ & $4(5.5)$ & 0.175 \\
0-1 & $63(88.7)$ & $68(93.1)$ & 0.034 \\
OKM grade C-D & $62(87.3)$ & $69(94.5)$ & 0.041 \\
\hline
\end{tabular}

Data are expressed as $n, \%$

$S A H$ subarachnoid hemorrhage, $m R S$ modified Rankin Scale

Table 3 Safety comparative analysis between the two groups

\begin{tabular}{llll}
\hline & SS group $(\mathbf{n}=\mathbf{7 1})$ & MS group $(\mathbf{n}=\mathbf{7 3})$ & P value \\
\hline Mortality, total, $n$ (\%) & $5(7.0)$ & $2(2.7)$ & 0.037 \\
Aneurysm rupture during procedure & $2(2.8)$ & $1(1.4)$ & 0.025 \\
Stroke, periprocedural & $1(1.4)$ & $0(0)$ & NA \\
Stroke, related to SAH at presentation & $1(1.4)$ & $1(1.4)$ & 0.545 \\
Related to SAH during follow-up & $0(0)$ & $0(0)$ & $\mathrm{NA}$ \\
Unrelated to aneurysm or its treatment & $1(1.4)$ & $0(0)$ & $\mathrm{NA}$ \\
Morbidity, total, $n$ (\%) & $9(12.7)$ & $3(4.1)$ & 0.029 \\
Aneurysm rupture during procedure & $3(4.2)$ & $2(2.7)$ & 0.035 \\
Stroke & $5(7.0)$ & $1(1.4)$ & 0.003 \\
SAH during follow-up & $1(1.4)$ & $0(0)$ & $\mathrm{NA}$ \\
\hline
\end{tabular}

Data are expressed as $n, \%$

$S A H$ subarachnoid hemorrhage

technique could increase the occlusion effect of aneurysms. Taken together, our results revealed that multiple overlapping stent-assisted coiling could improve the primary outcomes and clinical outcomes of patients with complex intracranial aneurysms.

\section{Safety comparative analysis between the two groups}

The safety outcomes of multiple overlapping stent-assisted coiling technique are shown in Table 3. Mortality included aneurysm rupture during procedure, stroke, (periprocedural or related to SAH at presentation), related to SAH during follow-up, and unrelated to aneurysm or its treatment. We found that the percentage of patients with aneurysm rupture during the procedure was significantly reduced in the MS group compared to the SS group $(P=0.025)$, thereby decreasing the total mortality $(P=0.037)$. However, no significant differences were observed in stroke, SAH, and unrelated outcomes caused mortality between the two groups. In terms of morbidity during the 12-month followup, multiple overlapping stent-assisted coiling treatment significantly decreased the 
occurrence of aneurysm rupture $(P=0.035)$ and stoke $(P=0.003)$. No significant difference was observed in SAH-caused morbidity between the two groups. Our results suggested that multiple overlapping stent-assisted coiling improved clinical safety of treatment for complex intracranial aneurysms.

\section{Discussion}

At present, there is no unified standard to define complex intracranial aneurysms. Complicated intracranial aneurysms mainly refer to aneurysms that are very difficult for surgical treatment due to their location, growth pattern, tumor size and neck width [20]. The location of aneurysm, collateral circulation, intraluminal thrombosis and calcified aneurysm wall affect the adverse consequences of arterial perforation and hemorrhagic spasm [21]. Due to the complexity of the aneurysm itself and the aneurysm-bearing artery, single surgical treatment or interventional embolization can cause the aneurysm to rupture, often resulting in unsatisfactory treatment [22, 23]. Optimizing the diagnosis and selecting the best treatment for intracranial aneurysms have become the focus of current clinical research.

Although craniotomy is still the first choice for some neurosurgeons in the treatment of intracranial aneurysms, endovascular embolization has become a new hot spot in the treatment of intracranial aneurysms. Coil embolization, balloon plastic surgery, stent-assisted aneurysm angioplasty and aneurysm artery occlusion are commonly used clinical endovascular interventional techniques [24, 25]. Traditional single stent-assisted coiling operation is a typical coil embolization technique, which is suitable for intracranial narrow carotid artery aneurysms and certain wide-neck artery aneurysms [26]. The coil can be used to partially embolize a wide-necked aneurysm in the acute stage of rupture to avoid bleeding. Moreover, single stent-assisted coiling can also be used to embolize overly tortuous tumor-bearing arteries, which are not suitable for treatment with stents or balloon-assisted techniques [27].

However, spring coil embolization technique for the treatment of aneurysms has the shortcomings of low complete packing rate and high recanalization rate, especially for large and huge aneurysms [28, 29]. Spring coil embolization for the treatment of intracranial aneurysms requires dense embolization [30]. Therefore, it is difficult for simple coil packing to treat complex intracranial aneurysms with complex morphology, especially fusiform [31, 32]. The current clinical solution to this limitation is to update materials and devices. Matrix microcoil is a new type of coil designed to reduce the recanalization rate post-aneurysm treatment [33]. It is coated with polyglycolic acidpolylactic acid on the metal surface, which can promote intra-aneurysm thrombosis and fibrosis and accelerate the formation of connective tissue. Thus, the increased thickness of the neck tissue of the aneurysm can effectively block the blood flow in the aneurysm, and the promoted coverage of the endometrial epithelial cells to the neck of the aneurysm can prevent the recurrence of the aneurysm [33]. However, applications of these new materials greatly increase the cost of coil embolization in the treatment of intracranial aneurysms.

In this study, we applied the multiple overlapping stent-assisted coiling technique to treat complex intracranial aneurysms. We placed a longer Leo self-expanding stent into the distal end of the aneurysm-carrying artery and chose a spring coil with appropriate 
length to embolize the aneurysm. Then we guided the second stent through the microguide wire to the distal end of the first stent to make the shorter second stent partially overlapping in the first stent to cover more area of the aneurysm. If the two stents could not cover the aneurysm, a third stent was guided to the distal end of the second stent to partially overlap with the second stent. A fourth stent was guided to the distal end of the third stent to partially overlap with the third stent, and so on until the aneurysm was completely covered by stents. During surgery, the stent provided a sufficiently large gap to ensure blood supply without obstruction. Multiple stents could assist different coils to embolize the aneurysm and solve technical problems such as insufficient support of a single stent and inadequate mesh density.

In fact, there were still some shortcomings in our research. Due to the limitation of resources and time, only 168 patients were included in this study, and the small number of participants might affect the accuracy of the results. In addition, considering that some patients had multiple chronic diseases at the same time and were taking different drugs, these physiological characteristics and outcomes were inevitably disturbed by factors other than surgical strategies. Our multiple overlapping stent-assisted coiling technique has higher requirements for the clinician's technique of performing surgery. In addition, each patient was evaluated by at least three experts who were not in this research group before receiving MS treatment. Patients who did not meet MS treatment standards were excluded from this study and received other related treatments by experts in our hospital.

\section{Conclusions}

In conclusion, the present study revealed that multiple overlapping stent-assisted coiling significantly reduced the major recurrence of aneurysms and contributed to reduced mortality and morbidity among patients. Coil embolization with multiple overlapping stenting improved the efficacy and safety for treating complex intracranial aneurysms.

\section{Methods}

\section{Study design}

To investigate the correlation between angiographic outcomes of patients with intracranial aneurysms and multiple overlapping stent-assisted coiling technique or single stentassisted coiling technique, a randomized and single-blinded clinical trial was performed in this study. We evaluated the therapeutic effects of multiple overlapping stent-assisted coiling and single stent-assisted coiling in the treatment of patients with intracranial aneurysms, in terms of the incidence of aneurysm recurrence and complications. Participants were allocated to investigate the therapeutic effects of multiple overlapping stentassisted coiling and single stent-assisted coiling from 2016 to 2019. The procedure of this research was approved by the ethics committee.

\section{Participants}

Patients who met the following criteria were recruited in this clinical trial: (1) over 18 years old; (2) with ruptured or unruptured 4 to $12 \mathrm{~mm}$ intracranial aneurysms; (3) agreed to receive endovascular coil embolization. Patients with the following situations 
were excluded from the trial: (1) with other cerebral arteriovenous malformation; (2) with primary parent vessel occlusion.

A total of 168 patients meeting the above criteria were recruited and assessed for our study. Participants were randomly divided into two groups (SS group and MS group) at a ratio of 1:1. Among all the participants, 9 patients discontinued our intervention, 8 patients moved away and lost contact, 3 participants changed their mind and refused to join this study any more, and 4 patients withdraw for other personal reasons. Thus, the data were collected from the remaining 144 participants (71 in SS group and 73 in MS group).

\section{Interventions}

A total of 168 patients diagnosed with complex intracranial aneurysms by digital subtraction angiography or computed tomographic angiography received pre-surgery examinations. According to the pathological conditions, patients were asked to take clopidogrel tablets $75 \mathrm{mg} /$ day and aspirin $100 \mathrm{mg} /$ day 3 days before surgery, or clopidogrel $300 \mathrm{mg}$ and aspirin $300 \mathrm{mg}$ preoperatively. Participants were randomly divided into two groups (SS group and MS group) at a ratio of 1:1.

Patients in the SS group received a single Leo stent (Leo, Balt, Montmorency, France) for endovascular treatment. A 6-French catheter (Envoy, Codman, Miami Lakes, FL) was used as guiding catheter in most cases. A telescopic access system was used including a long introducer (IVA 6F, Balt, Montmorency, France; or Shuttle, Cook Medical, IN, USA) and an intermediate access catheter (Neuron, Penumbra Inc., Alameda, USA; or Sofia, MicroVention, Aliso Vieja, CA). The single Leo stent was placed by a dedicated Vasco microcatheter (Balt, Montmorency, France). Coil embolization of the aneurysm, with another microcatheter, was performed by recrossing the stent or with the jailedcatheter technique. At the end of endovascular treatment, systemic heparinization was maintained for $24 \mathrm{~h}$ in most patients. For planned procedures, a loading dose of $300 \mathrm{mg}$ of clopidogrel and $320 \mathrm{mg}$ of aspirin was administered 1 day before and on the day of endovascular treatment. When stent placement was decided during the procedure, an IV bolus of abciximab $(0.25 \mathrm{mg} / \mathrm{kg})$ was administered a few minutes before stent deployment and followed by a continuous perfusion for $12 \mathrm{~h}$.

Patients in the MS group received multiple overlapping stent-assisted coiling technique for endovascular treatment. The $5 \mathrm{~F}$ universal catheter was firstly sent to the 6-French catheter by Seldinger technique for standard angiography. The three-dimensional rotational angiography of aneurysm was established to evaluate the size of each aneurysm and the diameter of aneurysm-carrying arteries, and the appropriate stent was selected accordingly. The microcatheter was delivered to the distal end of the aneurysm-carrying artery. A longer Leo self-expanding stent was implanted to cover the neck of the aneurysm, which reached the proximal and distal ends of aneurysm and normal artery wall. The stent was then half-relieved after radiography. Another microcatheter reached the aneurysm through the mesh of the stent, and a coil with appropriate length was selected. The first stent was completely released after the embolization. A micro-guidewire of 0.014 in. was placed in the first stent through the microcatheter and reached the distal end of the aneurysm. The Vasco microcatheter was guided to the first stent. The second stent was delivered, placed and released in the aneurysm. The second 
stent was relatively short, partially overlapping within the first stent, and completely covering the aneurysm. If necessary, the third stent can be delivered according to previously reported method [18].

All the above operations were performed by at least two senior interventional neuropathologists. Patients during the surgeries received pumping Tirofiban hydrochloride and systemic heparin after catheter placement. Patients received either of above operations were transferred into the intensive care unit for at least $24 \mathrm{~h}$. They were asked to take clopidogrel tablets $75 \mathrm{mg} /$ day for 6 weeks and aspirin $100 \mathrm{mg} /$ day for at least 6 months.

\section{Data collection}

The data of patients were obtained from a pre-constructed database which was established by the information directly collected by neurologists. The variables of the database included age, gender, mRS [34], NIHSS [35], number of aneurysms, aneurysm location, conditions of different aneurysms, aneurysm size, aneurysm morphology and OKM grades [34] of patient after each surgery.

\section{Outcomes}

The primary efficacy outcome measure was a composite end point consisting mostly of the occurrence of a major recurrence or a residual aneurysm at the time of follow-up angiography at 12 months, as adjudicated by an independent core lab blind to treatment allocation. The neurological symptoms induced by surgical operations were evaluated by the mRS. Lower mRS indicated a better neurological outcome. The blockage level of the aneurysm was evaluated by OKM grade. $\mathrm{C}$ and D levels indicated the complete occlusion of the aneurysms. The following conditions were defined as treatment failure: the coil was not placed in the correct position; SAH occurred during the perioperative period; other similar operations had to be performed for the same aneurysm; other serious complications occurred during the treatment.

The secondary outcomes of this research mainly composed of mortality and morbidity during the 12-month follow-up post the endovascular procedure. The causes of patients' death included aneurysm rupture, stroke, SAH and other unrelated conditions. The complications induced by the procedure included aneurysm rupture, stroke and SAH during the follow-up.

\section{Statistical analysis}

The categorized variables were shown as frequency or percentage. Mean and standard deviation were utilized to demonstrated the continuous variables. Chi-square test (or Fishers' exact test) was used to compare the classification variables. One-way analysis of variance and a Tukey's post hoc test were used to analyze the continuous variables, and contingency table Chi-square test was acquired for the comparison of outcomes among different groups. The SAS 17.0 software (SAS Institute Inc., Cary, NC, USA) was used for the statistical analysis in this study. 


\section{Acknowledgements}

None.

\section{Authors' contributions}

$L Y, J H, J Z, Z J$ did the experiments, collected the data, and wrote the manuscript. All authors read and approved the final manuscript.

\section{Funding}

None.

\section{Availability of data and materials}

Data could be obtained upon reasonable request to the authors.

\section{Declarations}

\section{Ethics approval and consent to participate}

This study was approved by ethical committee of Quanzhou First Hospital Affiliated to Fujian Medical University. All participants signed consent to participate.

\section{Consent for publication \\ All participants agreed to publish this work.}

\section{Competing interests}

The authors have no conflict of interest.

Received: 15 June 2021 Accepted: 19 September 2021

Published online: 09 October 2021

\section{References}

1. Etminan N, Rinkel GJ. Unruptured intracranial aneurysms: development, rupture and preventive management. Nat Rev Neurol. 2016;12(12):699-713.

2. Pace A, Mitchell S, Casselden E, Zolnourian A, Glazier J, Foulkes L, Bulters D, Galea I. A subarachnoid haemorrhagespecific outcome tool. Brain. 2018;141(4):1111-21.

3. Vlak MH, Algra A, Brandenburg R, Rinkel GJ. Prevalence of unruptured intracranial aneurysms, with emphasis on sex, age, comorbidity, country, and time period: a systematic review and meta-analysis. Lancet Neurol. 2011;10(7):626-36.

4. Vernooij MW, Ikram MA, Tanghe HL, Vincent AJ, Hofman A, Krestin GP, Niessen WJ, Breteler MM, van der Lugt A. Incidental findings on brain MRI in the general population. N Engl J Med. 2007:357(18):1821-8.

5. Weir B. Unruptured intracranial aneurysms: a review. J Neurosurg. 2002;96(1):3-42.

6. Hanel RA, Spetzler RF. Surgical treatment of complex intracranial aneurysms. Neurosurgery. 2008;62(Suppl 3):1289-97.

7. Cunha e Sa M. The use of deep hypothermia and cardiac arrest in the surgical treatment of large and complex intracranial circulation aneurysms. Acta Neurochir. 2010;152(6):1089-90.

8. Nussbaum ES. Surgical distal outflow occlusion for the treatment of complex intracranial aneurysms: experience with 18 cases. Neurosurgery. 2015;11(Suppl 2):8-16.

9. Nordmeyer H, Chapot R, Haage P. Endovascular treatment of intracranial atherosclerotic stenosis. Rofo. 2019;191(7):643-52.

10. Goktay AY, Senturk C. Endovascular treatment of thrombosis and embolism. Adv Exp Med Biol. 2017;906:195-213.

11. Kordzadeh A, Hanif MA, Ramirez MJ, Railton N, Prionidis I, Browne T. Prediction, pattern recognition and modelling of complications post-endovascular infra renal aneurysm repair by artificial intelligence. Vascular. 2021;29(2):171-82.

12. Kahn RA, Marin ML, Hollier L, Parsons R, Griepp R. Induction of ventricular fibrillation to facilitate endovascular stent graft repair of thoracic aortic aneurysms. Anesthesiology. 1998;88(2):534-6.

13. Lozano CS, Lozano AM, Spears J. The changing landscape of treatment for intracranial aneurysm. Can J Neurol Sci. 2019;46(2):159-65.

14. Park YK, Yi HJ, Choi KS, Lee YJ, Chun HJ. Intraprocedural rupture during endovascular treatment of intracranial aneurysm: clinical results and literature review. World Neurosurg. 2018;114:e605-15.

15. Griffin A, Reese V, Huseyinoglu Z, Niedzwiecki D, Yang L, Cutler A, Gonzalez LF, Zomorodi A, Smith T, Hauck EF. Predictors of clinical outcome after treatment of intracranial aneurysms with the pipeline embolization device. World Neurosurg. 2019;130:e666-71.

16. Sweid A, Atallah E, Herial N, Saad H, Mouchtouris N, Barros G, Gooch MR, Tjoumakaris S, Zarzour H, Hasan D, Chalouhi N, Rosenwasser RH, Jabbour P. Pipeline-assisted coiling versus pipeline in flow diversion treatment of intracranial aneurysms. J Clin Neurosci. 2018;58:20-4.

17. Lv X, Ge H, He H, Jiang C, LiY. A systematic review of pipeline embolization device for giant intracranial aneurysms. Neurol India. 2017;65(1):35-8.

18. Won YS, Rho MH, Chung EC, Hong HP, Kim SY, Park HJ, Choi YJ, Lee SY, Choi CS, Ihn YK. Multiple overlapping stentassisted coiling of complex aneurysms: a single-center experience. Neurol Res. 2015;37(3):189-96.

19. Kim BM, Kim DJ, Kim DI. Stent application for the treatment of cerebral aneurysms. Neurointervention. 2011;6(2):53-70. 
20. Sato K, Endo H, Fujimura M, Endo T, Matsumoto Y, Shimizu H, Tominaga T. Endovascular treatments in combination with extracranial-intracranial bypass for complex intracranial aneurysms. World Neurosurg. 2018;1 13:e747-60.

21. Zhao P, Wu HX, Paerhati R, Liu QL, Wang YY, Li G, Li XG, Wang DH. Management of 42 complex intracranial aneurysms in hybrid operating room. Zhonghua Yi Xue Za Zhi. 2017;97(11):810-3.

22. Ban SP, Cho WS, Kim JE, Kim CH, Bang JS, Son YJ, Kang HS, Kwon OK, Oh CW, Han MH. Bypass surgery for complex intracranial aneurysms: 15 years of experience at a single institution and review of pertinent literature. Oper Neurosurg. 2017;13(6):679-88.

23. Sanai N, Zador Z, Lawton MT. Bypass surgery for complex brain aneurysms: an assessment of intracranial-intracranial bypass. Neurosurgery. 2009;65(4):670-83.

24. Ihn YK, Shin SH, Baik SK, Choi IS. Complications of endovascular treatment for intracranial aneurysms: management and prevention. Interv Neuroradiol. 2018;24(3):237-45.

25. Imizu S, Kato Y, Sangli A, Oguri D, Sano H. Assessment of incomplete clipping of aneurysms intraoperatively by a near-infrared indocyanine green-video angiography (Niicg-Va) integrated microscope. Minim Invasive Neurosurg. 2008;51(4):199-203.

26. Im SH, Han MH, Kwon OK, Kwon BJ, Kim SH, Kim JE, Oh CW. Endovascular coil embolization of 435 small asymptomatic unruptured intracranial aneurysms: procedural morbidity and patient outcome. AJNR Am J Neuroradiol. 2009;30(1):79-84

27. Kim BM, Chung EC, Park SI, Choi CS, Won YS. Treatment of blood blister-like aneurysm of the internal carotid artery with stent-assisted coil embolization followed by stent-within-a-stent technique. Case report. J Neurosurg. 2007;107(6):1211-3.

28. Huang QH, Yang K, Cai X, Wang ZZ, Ma CY, Shun BY, Chen ZG. Endovascular embolization and microsurgical operation treatment of intracranial anterior circulation aneurysms. Zhong Nan Da Xue Xue Bao Yi Xue Ban. 2008;33(11):1050-2.

29. Ji Y, Wang ZG, Ding $X, Q u$ CC, Zhang QL. Recurrence of intracranial aneurysms after endovascular embolization: study of 70 cases. Zhonghua Yi Xue Za Zhi. 2008;88(19):1303-5.

30. Ortiz R, Song J, Niimi Y, Berenstein A. Rate of recanalization and safety of endovascular embolization of intracranial saccular aneurysms framed with GDC 360 coils. Interv Neuroradiol. 2008;14(4):397-401.

31. Chalouhi N, Jabbour P, Singhal S, Drueding R, Starke RM, Dalyai RT, Tjoumakaris S, Gonzalez LF, Dumont AS, Rosenwasser R, Randazzo CG. Stent-assisted coiling of intracranial aneurysms: predictors of complications, recanalization, and outcome in 508 cases. Stroke. 2013;44(5):1348-53.

32. Suh SH, Kim BM, Park SI, Kim DI, Shin YS, Kim EJ, Chung EC, Koh JS, Shin HC, Choi CS, Won YS. Stent-assisted coil embolization followed by a stent-within-a-stent technique for ruptured dissecting aneurysms of the intracranial vertebrobasilar artery. J Neurosurg. 2009;111(1):48-52.

33. Murayama Y, Tateshima S, Gonzalez NR, Vinuela F. Matrix and bioabsorbable polymeric coils accelerate healing of intracranial aneurysms: long-term experimental study. Stroke. 2003;34(8):2031-7.

34. Guimaraens L, Vivas E, Saldana J, Llibre JC, Gil A, Balaguer E, Rodriguez-Campello A, Cuadrado-Godia E, Ois A. Efficacy and safety of the dual-layer flow-diverting stent (FRED) for the treatment of intracranial aneurysms. J Neurointerv Surg. 2020;12(5):521-5.

35. Chalos V, van der Ende NAM, Lingsma HF, Mulder M, Venema E, Dijkland SA, Berkhemer OA, Yoo AJ, Broderick JP, Palesch YY, Yeatts SD, Roos Y, van Oostenbrugge RJ, van Zwam WH, Majoie C, van der Lugt A, Roozenbeek B, Dippel DWJ, Investigators MC. National institutes of health stroke scale: an alternative primary outcome measure for trials of acute treatment for ischemic stroke. Stroke. 2020;51(1):282-90.

\section{Publisher's Note}

Springer Nature remains neutral with regard to jurisdictional claims in published maps and institutional affiliations.

Ready to submit your research? Choose BMC and benefit from:

- fast, convenient online submission

- thorough peer review by experienced researchers in your field

- rapid publication on acceptance

- support for research data, including large and complex data types

- gold Open Access which fosters wider collaboration and increased citations

- maximum visibility for your research: over $100 \mathrm{M}$ website views per year

At BMC, research is always in progress.

Learn more biomedcentral.com/submissions 